\title{
Structure and Magnetic Properties of Iron/Iron-Oxide Nanoparticles Prepared by Precipitation from Solid State Solution
}

\author{
O. MilkoviČ $\check{C}^{a, b}$, J. Gamcová ${ }^{c, *}$, M. SOPKO $^{a}$ And I. ŠKORVÁNEK ${ }^{d}$ \\ ${ }^{a}$ Institute of Materials Research, Slovak Academy of Sciences, Watsonova 47, 04001 Košice, Slovakia \\ ${ }^{b}$ Institute of Materials, Faculty of Metallurgy, Technical University of Košice, Letná 9, 04001 Košice, Slovakia \\ ${ }^{c}$ Institute of Physics, Faculty of Science, P.J. Šafárik University, Park Angelinum 9, 04154 Košice, Slovakia \\ ${ }^{d}$ Institute of Experimental Physics, Slovak Academy of Sciences, Watsonova 47, 04001 Košice, Slovakia \\ The influence of precipitation temperature on structural and magnetic properties of iron/iron-oxide nanopar- \\ ticles is investigated. Nanoparticles were prepared by precipitation of $\gamma$-Fe precipitates in $\mathrm{Cu}-\mathrm{Fe}$ solid solution and \\ subsequently isolated by matrix dissolution. Precipitation annealing temperatures were 773,873 , and 973 K. Nano- \\ particles core-shell structure and morphology were characterized by X-ray diffraction, high-resolution transmission \\ electron microscopy, and selected area electron diffraction. These measurements showed that average diameter of \\ nanoparticles increases with precipitation temperature from $8.5 \mathrm{~nm}$ to $20.5 \mathrm{~nm}$. The measurements of magnetiza- \\ tion as a function of temperature and applied field have been performed by SQUID magnetometer in temperature \\ range from $5 \mathrm{~K}$ to $200 \mathrm{~K}$.
}

DOI: 10.12693/APhysPolA.131.747

PACS/topics: 61.46.Df

\section{Introduction}

In last period various scientific and industrial groups are devoted in development and preparation of nanostructure metal oxides like nanoparticles (NPs) [1]. The structural and magnetic properties of $\mathrm{Fe} / \mathrm{Fe}_{3} \mathrm{O}_{4}$ NPs has been studied in different works [2-4]. The shape of the NPs depends on the preparation methods. Several studies have demonstrated the controllable synthesis of nonspherical iron oxide NPs with cubic [5, 6], hexagonal [7], and rod [8-10] morphologies. It was shown that the size of spherical $\mathrm{Fe}_{3} \mathrm{O}_{4} \mathrm{NPs}$ prepared by hydrolysis can be in the range from 10 to $40 \mathrm{~nm}$ in mean diameter. With the increase of NPs mean diameter from 12 to $40 \mathrm{~nm}$ their coercivity drastically increased to $7.958 \mathrm{kA} / \mathrm{m}$ and the magnetic saturation to $87.7 \mathrm{~A} \mathrm{~m}^{2} / \mathrm{kg}$.

In this work, spherical magnetic core-shell NPs were synthesized using the precipitation process in solid state of $\mathrm{Cu}-\mathrm{Fe}$ alloy. The crystalline structure and size of NPs were characterized by X-ray diffraction (XRD), highresolution transmission electron microscopy (HRTEM), selected area electron diffraction (SAED) techniques and the magnetic properties were investigated by SQUID magnetometer.

\section{Experimental procedure}

The binary $\mathrm{Cu}-\mathrm{Fe}$ alloy with $1.23 \mathrm{wt} \% \mathrm{Fe}$ was used as starting material for a growth of the NPs. The samples were precipitation annealed in pure argon atmosphere

*corresponding author; e-mail: jana.gamcova@upjs.sk and quenched in cold water. Temperatures of precipitation annealing were $773 \mathrm{~K}$ (sample K), $873 \mathrm{~K}$ (sample $\mathrm{F}$ ), and $973 \mathrm{~K}$ (sample A). The holding time on certain temperature was $3 \mathrm{~h}$. The precipitates were subsequently extracted from the parent alloy by using a chemical solution method. Observing the morphology, shape and size distribution of NPs using TEM and determining crystal state using SAED, was done on JEOL JEM-2000FX and JEOL JEM-2000SX microscope (at an acceleration voltage of $200 \mathrm{keV}$ ). Sample preparation for TEM involved dispersing in pure ammonia of aqueous solution and deposition of a drop of colloidal solution onto a molybdenum grid coated with a carbon film.

The XRD measurements were carried out on P02.1 experimental station located at PETRA III storage ring in DESY, Hamburg, Germany. High-energy X-ray diffraction experiments were performed in transmission geometry. The monochromatic beam had energy $59.82 \mathrm{keV}$ $(\lambda=0.207 \AA)$. The diffracted patterns were recorded using an image plate detector Perkin Elmer 1621 $(2048 \times 2048$ pixels, pixel size $200 \mu \mathrm{m} \times 200 \mu \mathrm{m})$. The NPs were placed in a quartz capillary with thickness of $1 \mathrm{~mm}$. One diffraction pattern was acquired in $10 \mathrm{~s}$. Diffraction patterns were integrated using the FIT2D software [11]. The sample-detector distance, detector orthogonality with respect to the incoming beam was determined by fitting of reference $\mathrm{CeO}_{2}$ powder. The measurements of magnetization as a function of temperature and applied field have been performed by a commercial SQUID magnetometer Measuring System model MPMSXL-5 (Quantum Design, USA) equipped with $5 \mathrm{~T}$ superconducting magnet in temperature range from $5 \mathrm{~K}$ to $200 \mathrm{~K}$. 


\section{Result and discussion}

In Fig. 1 there is shown TEM analysis of NPs annealed at different temperatures $(\mathrm{K}=773 \mathrm{~K}, \mathrm{~F}=873 \mathrm{~K}, \mathrm{~A}$ $=973 \mathrm{~K})$. In each annealed state NPs are well-separated with near-spherical shape, obvious aggregation can be observed as well. The average NPs size in the case of sample A is $20.5 \mathrm{~nm}$ and the size of particles is relatively homogeneous. The average size of nanoparticles in sample $\mathrm{F}$ and $\mathrm{K}$ is 12.5 and $8.5 \mathrm{~nm}$, respectively. NPs size distributions are in $\mathrm{F}$ and $\mathrm{K}$ cases narrower compared to sample A.
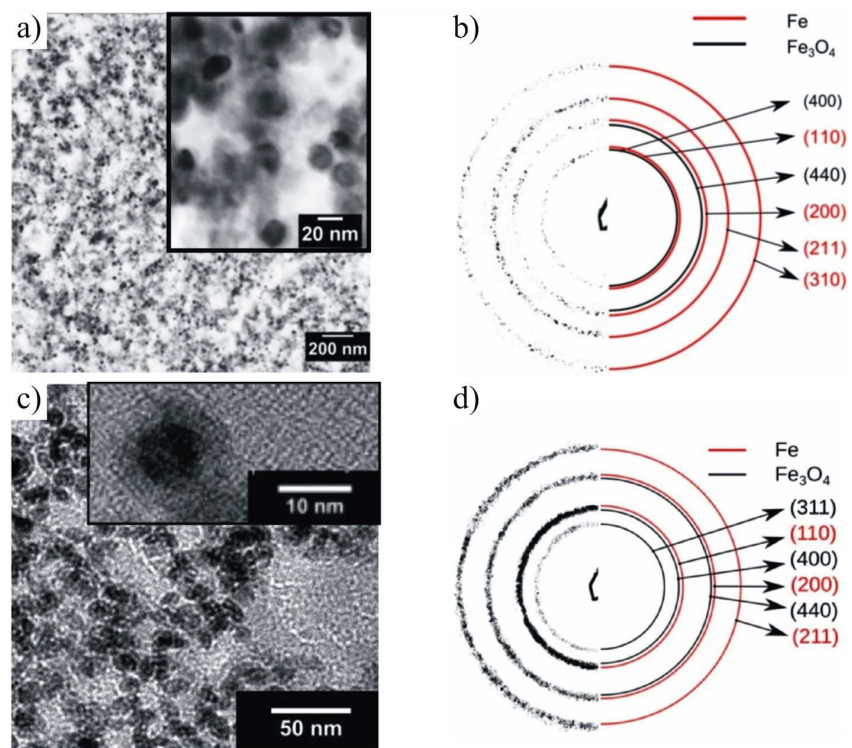

d)
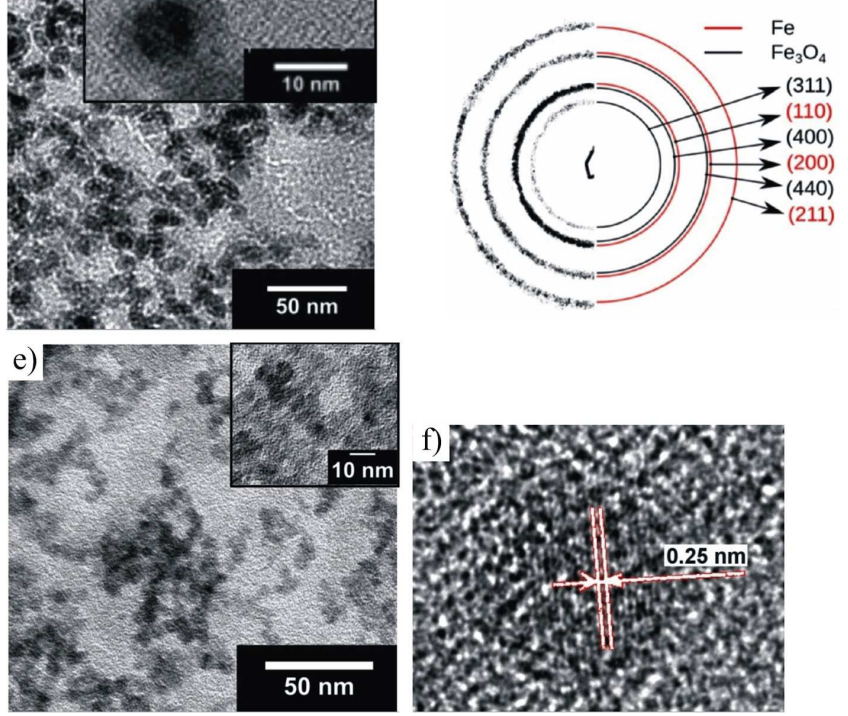

Fig. 1. TEM and SAED images of nanoparticles of sample A (a) and (b), sample F (c) and (d), TEM and HRTEM images of sample $\mathrm{K}(\mathrm{e})$ and (f).

In Fig. $1 b$ and $d$ there are shown SAED patterns of $A$ and F samples. Diffraction patterns of NPs are marked by their corresponding indices of crystal planes of pure iron $\left(\alpha\right.$-Fe) and magnetite $\left(\mathrm{Fe}_{3} \mathrm{O}_{4}\right)$ phase. Magnetite is characterized by broad diffraction rings which indicate the low crystallinity of the NPs phase.

SAED patterns and TEM images constitute the experimental evidence of the core-shell $\left(\alpha-\mathrm{Fe} / \mathrm{Fe}_{3} \mathrm{O}_{4}\right)$ structure. The HRTEM image in Fig. 1f shows detail of $\mathrm{K}$ sample NPs. The measured lattice spacing is $0.25 \mathrm{~nm}$ which corresponds to (311) plane of the $\mathrm{Fe}_{3} \mathrm{O}_{4}$ crystalline phase. In the case of the smallest K NPs, the $\alpha$-Fe in core is missing, therefore these NPs consist only from one phase which corresponds to oxide shell $\mathrm{Fe}_{3} \mathrm{O}_{4}$, in contrast to the core-shell structure of NPs with larger diameter.

Radially integrated diffraction patterns obtained from investigated NPs are documented in Fig. 2. Profiles are refined employing the Rietveld method using two phases. Sample A and F: $\alpha$-Fe (ICSD 44863; space group (S.G.) Im $3 m$ ). Sample A, F, and $\mathrm{K}: \mathrm{Fe}_{3} \mathrm{O}_{4}$ (ICSD 82441; S.G. $F m 3 m$ ). Diffraction profiles show that sample K, with the smallest size distribution, is without $\alpha$-Fe core. Based on differential curves can be stated that all reflections are refined and the additional phase is not presented in the diffraction patterns.

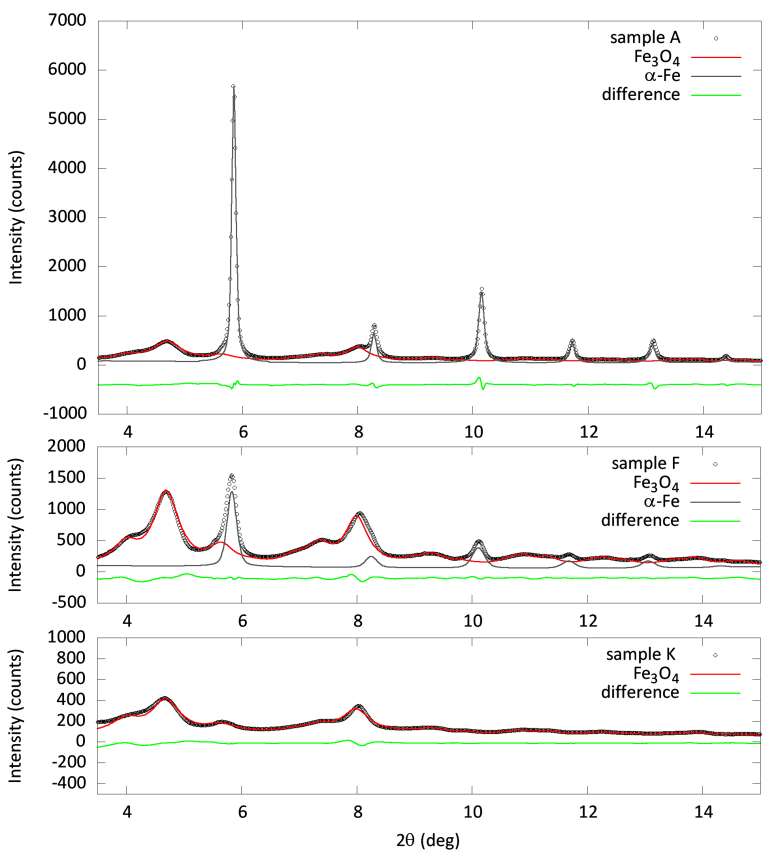

Fig. 2. XRD pattern sample A (973 K), F ( $873 \mathrm{~K})$ and $\mathrm{K}(773 \mathrm{~K})$.

Fitted structure parameters and volume ratio of the identified phases are summarized in Table I.

TABLE I

Fitted structure parameters and volume ratio of the identified phase.

\begin{tabular}{c|c|c|c|c|c|c}
\hline \hline & \multicolumn{2}{|c|}{$\begin{array}{c}\text { Volume } \\
{[\%]}\end{array}$} & \multicolumn{2}{c|}{$\begin{array}{c}\text { Lattice } \\
\text { parameter }[\AA]\end{array}$} & \multicolumn{2}{c}{$\begin{array}{c}\text { Crystalline } \\
\text { size }[\mathrm{nm}]\end{array}$} \\
\hline & $\alpha$-Fe & $\mathrm{Fe}_{3} \mathrm{O}_{4}$ & $\alpha$-Fe & $\mathrm{Fe}_{3} \mathrm{O}_{4}$ & $\alpha$-Fe & $\mathrm{Fe}_{3} \mathrm{O}_{4}$ \\
\hline $\mathrm{A}$ & 40.5 & 59.5 & 2.865 & 8.380 & 15.4 & 2.3 \\
$\mathrm{~F}$ & 8.5 & 91.5 & 2.883 & 8.401 & 7 & 2.4 \\
$\mathrm{~K}$ & 0 & 100 & - & 8.398 & 0 & 2.3
\end{tabular}

It is very interesting to compare the lattice parameter and volume fraction of the NPs cores. Maximal lattice parameter of the $\alpha-\mathrm{Fe}$ is determined for the lower volume fraction of the NPs core. We can explain this effect by lattice deformation at the core-shell interface after the oxidation of NPs during the isolation process. While noble NPs are uncovered by chemical dissolution of $\mathrm{Cu}$ 
matrix, NPs surface is passivated by oxidation. Passivated layer is formed in core-shell interface and generates lattice strains in the core volume close to the interface. Effect of strained lattice is more evident in increase of lattice parameter value if there is higher ratio between strained volume and overall volume of the core or in case the average NPs size is larger.

Rate of passivation process is too high for the formation of well crystalline oxide layer while NPs are forming a stable passive layer with thickness of about $4 \mathrm{~nm}[12,13]$. TEM observation of oxide shell thickness shows a good agreement with mentioned theory in [12]. Moreover the formation of the low crystalline oxide shell results in the broadened diffraction peaks of the $\mathrm{Fe}_{3} \mathrm{O}_{4}$ phase.

The dependence of magnetic properties of NPs on temperature and their mean diameter was investigated (Fig. 3). The saturated magnetization is smaller in compare with bulk counterparts of $\mathrm{Fe}_{3} \mathrm{O}_{4}$ ( $\mathrm{MS}=92$ $100 \mathrm{~A} \mathrm{~m}^{2} / \mathrm{kg}$ ) [14]. This can be attributed to the surface disorder or spin canting at the particles surface $[15,16]$.
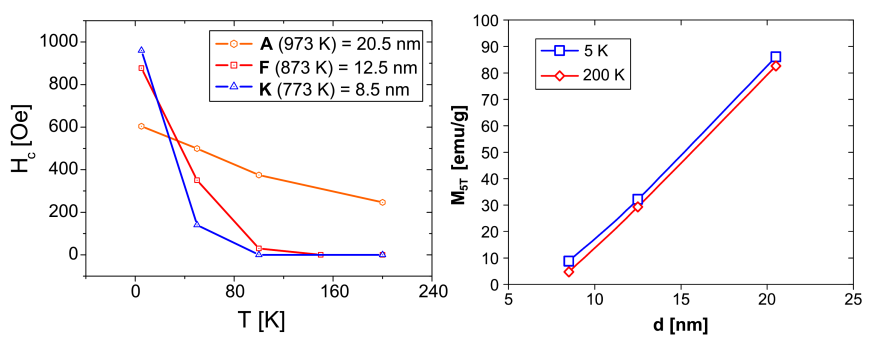

Fig. 3. The temperature dependences of coercivity (left) and the particle size dependences of magnetization $M_{5} \mathrm{~T}$ measured in magnetic field at $5 \mathrm{~T}$ (right).

The coercivity, $H_{c}$, was determined from the hysteresis loop measured at temperatures 5, 50, 100, and $200 \mathrm{~K}$. As it can be seen from Fig. 3, the $H_{c}$ value increases with the decrease of temperature. At lower temperature, it is expected the occurring of blocking effect. The coercivity of $20 \mathrm{~nm}$ NPs (sample A) linearly decrease with temperature in measured temperature interval. The coercivity of 12.5 and $8.5 \mathrm{~nm}$ NPs (sample F and K) markedly decrease with temperature. At temperature $100 \mathrm{~K}$ the dependence change and samples show just slight temperature dependence of $H_{c}$. The decrease of $H_{c}$ (measured at $5 \mathrm{~K}$ ) with increase of NPs size suggests that above temperatures where $H_{c}=0 \mathrm{~A} / \mathrm{m}$ (sample $\mathrm{F}=150 \mathrm{~K}$ and sample $\mathrm{K}=200 \mathrm{~K}) \mathrm{NPs}$ are superparamagnetic. This temperature is referred as blocking temperature.

\section{Conclusions}

We showed that metallic Fe NPs, with size of 20, 12.5 , and $8.5 \mathrm{~nm}$, synthesized by a solid state precipitation method, consist of $\alpha$-Fe core and $\mathrm{Fe}_{3} \mathrm{O}_{4}$ shell with thickness of 2-4 nm. The results of average particle size and structure characteristics observed using TEM and SAED are consistent with XRD analysis. The decrease of the temperature of precipitation annealing causes decrease of the diffusion intensity, so precipitates are smaller and the smallest $8.5 \mathrm{~nm} \mathrm{NPs}$ consist only of $\mathrm{Fe}_{3} \mathrm{O}_{4}$. The core-shell NPs have relatively high saturation magnetization (from $M_{5} \mathrm{~T}=82.6 \mathrm{~A} \mathrm{~m}^{2} / \mathrm{kg}$ for $20.5 \mathrm{~nm}$ to $M_{5 \mathrm{~T}}=29.3 \mathrm{~A} \mathrm{~m}^{2} / \mathrm{kg}$ for $\left.12.5 \mathrm{~nm}\right)$. The crystallite size, $\alpha$-Fe fraction, and saturation of magnetization decrease with temperature of precipitation annealing. NPs with diameter smaller than $\approx 12.5 \mathrm{~nm}$ are superparamagnetic due to thermal fluctuation. These results describe way for production of core-shell particles of various metals that are not currently synthesized in bulk using precipitation from solid state solution.

\section{Acknowledgments}

Part of this research were carried out at the light source PETRA III (beamline P02.1) at DESY, a member of the Helmholtz Association (HGF). O.M. thanks to financial support of research project DAAD A/14/05531.

\section{References}

[1] D. Ramimoghadam, S. Bagheri, S.B.A. Hamid, J. Magn. Magn. Mater. 368, 207 (2014).

[2] H. Yan, Ch. You, Z. Song, B. Yu, Y. Shen Mater. Chem. Phys. 113, 46 (2009).

[3] H. Iida, K. Takayanagi, T. Nakanishi, T. Osaka, J. Coll. Interf. Sci. 314, 274 (2007).

[4] C. de Montferrand, L. Hu, I. Milosevic, V. Russier, D. Bonnin, L. Motte, A. Brioude, Y. Lalatonne, Acta Biomater. 9, 6150 (2013).

[5] A. Shavel, L.M. Liz-Marzan, Phys. Chem. Chem. Phys. 11, 3762 (2009).

[6] H. Yang, T. Ogawa, D. Hasegawa, M. Takahashi, J. Appl. Phys. 103, 07D526 (2008).

[7] J. Cheon, N.-J. Kang, S.-M. Lee, J.-H. Lee, J.H. Yoon, S.J. Oh, J. Am. Chem. Soc. 126, 1950 (2004).

[8] S.-J. Park, S. Kim, S. Lee, Z.G. Khim, K. Char, T. Hyeon, J. Am. Chem. Soc. 122, 8581 (2000).

[9] M. Zhu, G. Diao, J. Phys. Chem. C 115, 18923 (2011).

[10] Q. He, T. Yuan, S. Wei, N. Haldolaarachchige, Z. Luo, D.P. Young, A. Khasanov, Z. Guo, Angew. Chem. Int. Ed. 51, 8842 (2012).

[11] A.P. Hammersley, FIT2D: An Introduction and Overview, ESRF Internal Report, ESRF97HA02T, 1997.

[12] K.K. Fung, B. Qin, X.X. Zhang, Mater. Sci. Eng. 286, 135 (2000).

[13] O. Milkovič, G. Janak, S. Niznik, S. Longauer, L. Frohlich, Mater. Lett. 64, 144 (2010).

[14] R. Cornell, U. Schwertmann, The Iron Oxides, WileyVCH, Weinheim 2003.

[15] C.-R. Lin, Y.-M. Chu, S.-C. Wang, Mater. Lett. 60 , 447 (2006).

[16] X. Batlle, A. Labarta, J. Phys. D Appl. Phys. 35, R15 (2002). 